\title{
Neoadjuvant Chemotherapy Followed by Surgery versus Primary Surgery in Advanced Epithelial Ovarian Cancer: A Review of Outcomes at National Institute of Cancer Research Hospital in Bangladesh
}

\author{
Farhana Kalam¹* (1), Shahana Pervin1, K. M. Nazmul Islam Joy², Johirul Islam³, \\ Annekathryn Goodman ${ }^{4}$ \\ ${ }^{1}$ Gynaecological Oncology Department, National Institute of Cancer Research \& Hospital (NICRH), Dhaka, Bangladesh \\ ${ }^{2}$ Neurology Department, SShMC, Dhaka, Bangladesh \\ ${ }^{3}$ Cancer Epidemiology, NICRH, Dhaka, Bangladesh \\ ${ }^{4}$ Harvard Medical School, Division Gynecologic Oncology Massachusetts General Hospital, Boston, USA \\ Email: ^ovikalam@yahoo.com, shahana.pervin@yahoo.com,kmnazmul@gmail.com,dr.johir@gmail.com
}

How to cite this paper: Kalam, F., Pervin, S., Joy, K.M.N.I., Islam, J. and Goodman, A. (2021) Neoadjuvant Chemotherapy Followed by Surgery versus Primary Surgery in Advanced Epithelial Ovarian Cancer: A Review of Outcomes at National Institute of Cancer Research Hospital in Bangladesh. Journal of Cancer Therapy, 12, 621-633. https://doi.org/10.4236/jct.2021.1211054

Received: October 21, 2021

Accepted: November 16, 2021

Published: November 19, 2021

Copyright $\odot 2021$ by author(s) and Scientific Research Publishing Inc. This work is licensed under the Creative Commons Attribution International License (CC BY 4.0).

http://creativecommons.org/licenses/by/4.0/

\section{(c) (i) Open Access}

\begin{abstract}
Introduction: This study evaluated the difference in operative and clinical outcomes for patients with advanced ovarian cancer after primary debulking surgery (PDS) versus neoadjuvant chemotherapy (NACT) followed by interval debulking surgery (IDS) in Bangladesh. Methods: Sixty patients with advanced epithelial ovarian cancer presenting to the department of Gynaecological Oncology at the National Institute of Cancer Research and Hospital were prospectively enrolled. Thirty patients underwent primary debulking surgery and thirty patients received NACT followed by IDS. Results: In the PDS and IDS groups respectively, $56.7 \%$ and $50 \%$ of patients presented with stage IIIC and $67.7 \%$ and $56.7 \%$ respectively had serious papillary type histopathology. Duration of surgery, amount of blood loss and total hospital stay were significantly lower $(\mathrm{p}<0.001)$ in IDS group than in the PDS group. There was a statistically significant difference in postoperative tumor residuals between IDS and PDS patients. Complete tumor resection (R0) was obtained in $24(80 \%)$ of IDS patients versus 13 (43.3\%) PDS patients. In fifteen months of follow-up, 21 (70\%) in the PDS group and 5 (16.7\%) in the IDS group recurred $(\mathrm{p}=0.021)$. Median progression free survival in PDS patients was twelve months while that of the IDS group was seventeen months. There was one death at 45 days in the PDS group. No other deaths were documented at fifteen months of follow-up. Conclusion: Interval debulking surgery has a more
\end{abstract}


favorable outcome than primary debulking surgery on progression free survival in advanced ovarian cancer patients and permits a less aggressive surgery to be performed in Bangladesh.

\section{Keywords}

Neoadjuvant Chemotherapy, Interval Debulking Surgery, Primary Debulking Surgery, Cytoreductive Surgery, Epithelial Ovarian Cancer, Bangladesh

\section{Introduction}

Ovarian cancer is the deadliest of all gynecological cancers. Even though new treatment approaches have been introduced, the five-year survival is low [1] [2] [3] [4]. Ovarian cancer is commonly diagnosed when it has already spread to the upper abdomen and distant areas because of initial vague and non-specific signs and symptoms. The current standard treatment of advanced ovarian cancer (stage III/IV) can either be primary debulking surgery (PDS) followed by chemotherapy or neoadjuvant chemotherapy (NACT) followed by interval debulking surgery (IDS) [5]. Debulking or cytoreductive surgery typically includes a total abdominal hysterectomy with bilateral salpingo-oophorectomy (TAH-BSO), complete omentectomy and resection of any metastatic disease.

Resectability of disease depends on the skills of the surgeon and the extent of disease. Optimal cytoreduction is difficult if there is an extensive disease involving the upper abdomen or the undersurface of diaphragm. While optimal cytoreduction is an important prognostic factor for the survival of patients, extensive surgical resection increases postoperative morbidity [6] [7].

Neoadjuvant chemotherapy (NACT), followed by surgery is a therapeutic approach for extensive disease when complete surgical resection is not initially possible either due to bulky or diffusely unresectable disease or because of patients' medical comorbidities. NACT significantly reduces the tumor burden before surgery and allows an easier and optimal cytoreduction [8] [9]. It also decreases the morbidity, blood loss, and intensive care unit (ICU) and hospital stays [10].

This study compares the outcomes and peri-operative morbidities of primary debulking surgery versus NACT followed by surgery in Bangladeshi women with advanced ovarian cancer.

\section{Methods}

This prospective quasi experimental study was done between November 2017 to October 2019 in the department of Gynaecological Oncology, National Institute of Cancer Research and Hospital (NICRH), Dhaka, Bangladesh. Sixty patients with a diagnosis of ovarian cancer by histopathology, fine needle aspiration cytology (FNAC), and imaging studies such as ultrasound or CT scan were included in the study. Data was collected in a pre-designed data collection form. 
Patients were divided into two groups and assigned either to primary debulking surgery (PDS) followed by six courses of platinum-based chemotherapy or three courses of neoadjuvant platinum-based chemotherapy followed by interval debulking surgery (IDS), followed by three courses of platinum-based chemotherapy. Eligibility criteria was as follows: Patients were assigned to their treatment group based on both radiological and exam findings. Those patients with a fixed pelvic mass, large ascites, pleural effusions, and/or diaphragmatic disease were assigned to receive neoadjuvant chemotherapy followed by interval debulking surgery.

Patients were regularly evaluated after completion of chemotherapy for evidence of disease recurrence over fifteen months of follow-up. The follow-up schedule was every three months and included clinical examination, transvaginal and transabdominal ultrasound and CA-125 assays. A computed tomography (CT scan)/Magnetic Resonance Imaging (MRI) scan was ordered if clinical examination or laboratory testing was abnormal. Results of the study was calculated and analyzed by standard statistical methods. Data was expressed as mean + SD. A value of $\mathrm{p}<0.05$ was considered statistically significant. The data was analyzed with the SPSS for Windows (IBM SPSS Statistics for Windows, version 22.0, Armonk, NY: IBM Corp) software.

\section{Results}

Median age of the PDS group was 49 years while that of the IDS group was 55 years. Mean body mass indices of both groups were below $25 \mathrm{~kg} / \mathrm{m}^{2}$ which was not statistically significant. Pleural effusion was noted in four patients $(13.3 \%)$ in the PDS group compared to one patient (3.3\%) in the IDS group. Distension of the abdomen with ascites was the chief complaint in both groups (eight in PDS and six in IDS). Pain and palpable abdominal masses were present in five and one patients respectively in PDS and in IDS groups. Median tumor size was $12.12 \mathrm{~cm}$ in PDS and $10.85 \mathrm{~cm}$ in IDS groups. Pre NACT and post NACT CA-125 blood levels in IDS patients were significantly different $(\mathrm{p}<0.001)$. Twenty-two patients had normalization of CA 125 levels after three cycles of NACT, six women had a reduction in the CA 125, and two women had no change in CA 125 levels. There were no significant differences were found in respect to CEA blood levels (Table 1).

Table 2 summarizes the histopathologic subtypes of epithelial ovarian cancer among the sixty patients. There was no statistical difference between those undergoing upfront versus interval cytoreductive surgeries.

Surgery-related variables are shown in Table 3. In the PDS group, the median length of operations was 2.75 hours compared to 2.5 hours in the IDS group. This difference was statistically significant. The amount of blood loss in PDS patients $(720 \mathrm{ml})$ was significantly higher than IDS patients $(496.67 \mathrm{ml})(\mathrm{p}<0.001)$. The volume of ascitic fluid found in PDS $(1038.33 \mathrm{ml})$ was also significantly higher than the similar fluid found in IDS $(86.67 \mathrm{ml})(\mathrm{p}<0.001)$. A complete cytoreduction (residual disease to R0) occurred in $24(80 \%)$ of IDS patients 
Table 1. Baseline characteristics of sixty patients assigned to either Primary Debulking Surgery (PDS) or Interval Debulking Surgery (IDS).

\begin{tabular}{|c|c|c|c|}
\hline \multicolumn{4}{|c|}{ Baseline Characteristics } \\
\hline Variables & $\begin{array}{c}\text { PDS } \\
(\mathrm{N}=30)^{*}\end{array}$ & $\begin{array}{c}\text { IDS } \\
(\mathrm{N}=30)^{*}\end{array}$ & p-value \\
\hline Median age & 49.0 & 55.0 & 0.196 \\
\hline BMI (mean, SD) & 24.29 & 23.88 & 0.705 \\
\hline \multicolumn{4}{|l|}{ Clinical presentation $(\mathrm{N}, \%)$} \\
\hline Mass & $4(13.3 \%)$ & $3(10.0 \%)$ & \\
\hline Distension & $8(26.7 \%)$ & $6(20.0 \%)$ & \\
\hline Anorexia and nausea & $1(3.3 \%)$ & $2(6.7 \%)$ & \\
\hline Both pain \& mass & $5(16.7 \%)$ & $1(3.3 \%)$ & \\
\hline Median tumor size $(\mathrm{cm})$ & 12.12 & 10.85 & 0.235 \\
\hline $\begin{array}{c}\text { CA-125 }(\mathrm{U} / \mathrm{mL}) \text { level } \\
\text { (pre NACT vs. post NACT) }\end{array}$ & - & $\begin{array}{c}1490.77( \pm 1445.37) \\
\text { vs. } \\
91.599( \pm 219.87)\end{array}$ & $<0.001$ \\
\hline CEA (ng/mL) level & $3.6490(3.11110)$ & $2.7107(1.41195)$ & 0.138 \\
\hline \multicolumn{4}{|l|}{ ECOG Performance status (N, \%) } \\
\hline$P F S 0$ & $3(10 \%)$ & $3(10 \%)$ & \\
\hline$P F S 1$ & $16(53.3 \%)$ & $13(43.3 \%)$ & 0.797 \\
\hline$P F S 2$ & $11(36.7 \%)$ & $14(46.7 \%)$ & \\
\hline
\end{tabular}

${ }^{\star}$ PDS $=$ Primary Debulking Surgery +6 cycle chemotherapy; IDS = 3 Cycles Neoadjuvant chemotherapy (NACT) + Interval Debulking Surgery + 3 cycles chemotherapy.

Table 2. Baseline characteristics of sixty patients assigned to either Primary Debulking Surgery (PDS) or Interval Debulking Surgery (IDS).

\begin{tabular}{|c|c|c|c|}
\hline \multicolumn{4}{|c|}{ Histopathological Characteristics } \\
\hline Histopathology & $\begin{array}{c}\text { PDS } \\
(\mathrm{N}=30)^{*}\end{array}$ & $\begin{array}{c}\text { IDS } \\
(\mathrm{N}=30)^{*}\end{array}$ & $\mathrm{p}$-value \\
\hline Serous papillary & 20 & 17 & 0.235 \\
\hline Mucinous & 8 & 11 & 0.160 \\
\hline Endometrioid & 1 & 1 & 0.739 \\
\hline Clear cell & 0 & 1 & \\
\hline Mixed & 1 & 0 & \\
\hline \multicolumn{4}{|l|}{ Grade } \\
\hline Well differentiated (Grade 1) & $1(33.3 \%)$ & $5(16.7 \%)$ & \\
\hline Moderately Differentiated (Grade 2) & $11(36.7 \%)$ & $7(23.3 \%)$ & 0.174 \\
\hline Poorly Differentiated (Grade 3) & $18(60.0 \%)$ & $18(60.0 \%)$ & \\
\hline
\end{tabular}

${ }^{\star}$ PDS $=$ Primary Debulking Surgery +6 cycle chemotherapy; IDS = 3 Cycles Neoadjuvant chemotherapy (NACT) + Interval Debulking Surgery + 3 cycles chemotherapy. 
Table 3. The comparison of surgery and hospital stay of sixty patients assigned to either Primary Debulking Surgery (PDS) or Interval Debulking Surgery (IDS).

\begin{tabular}{cccc}
\hline \multicolumn{4}{c}{ Comparison of Surgery and Hospital Stay } \\
\hline Variables & PDS & IDS & p-value \\
\hline Median length of operation (hr) & 2.75 & 2.50 & 0.018 \\
Amount of blood loss (ml) & 727.59 & 496.67 & $<0.001$ \\
Amount of ascetic fluid (ml) & 1038.33 & 86.67 & $<0.001$ \\
Residual diseases (R)** & & & \\
$R 0$ & $13(43.3 \%)$ & $24(80 \%)$ & \\
$R 1$ & $9(30 \%)$ & $4(13.3 \%)$ & 0.012 \\
$R 2$ & $8(26.7 \%)$ & $2(6.7 \%)$ & \\
Transfusion needed (unit) & 1.13 & 1.0 & 0.456 \\
Hospital stay (days) & 14.0 & 12.0 & $<0.001$ \\
\hline
\end{tabular}

${ }^{*}$ PDS $=$ Primary Debulking Surgery +6 cycle chemotherapy; IDS $=3$ Cycles Neoadjuvant chemotherapy $(\mathrm{NACT})+$ Interval Debulking Surgery +3 cycles chemotherapy. ${ }^{*} \mathrm{R} 0=$ no residual disease; $\mathrm{R} 1$ = microscopic disease; $\mathrm{R} 2$ = macroscopic disease [11].

compared to $13(43.3 \%)$ of PDS patients. R1 (microscopic) residual disease was noted in nine (30\%) PDS patients and four (13.3\%) IDS patients. Residual R2 (macroscopic) disease was noted in eight (26.7\%) PDS versus two (6.7\%) IDS patients. These differences were statistically significant. Median hospital days for PDS patients was 14 days while for IDS patients was 12 days. This difference was statistically significant ( $\mathrm{p}<0.001$ ).

Post-operative adverse events and mortality are shown in Table 4. Hypoalbuminemia was found in twelve patients in the PDS group and in eleven patients in the IDS group. In the PDS group, there were eleven events of electrolyte Imbalance compared to five patients in the IDS group. Eleven patients in both arms developed infections. Nausea \& vomiting were reported in seven and five patients in PDS and in IDS groups respectively. The other complications include hypotension, fever, diarrhea, intestinal resection, paralytic ileus, and renal complications. Paralytic ileus was the only difference of statistically significance.

There was one postoperative death in the PDS group that occurred within 45 days of surgery. This patient died at home after several days of anorexia and abdominal distention. She was thought to have had an intestinal obstruction.

The development of tumor or ascites at different follow-ups is presented in Table 5. At six months of follow-up, there was only one instance of a mass or mass with ascites in PDS patients. At nine months of follow-up period, there were two reports of masses and one additional ascites in the PDS group. These differences were statistically not significant. In the last two consecutive follow-ups, significant differences were noted as PDS patients experienced more 
Table 4. Postoperative complications for sixty patients assigned to either Primary Debulking Surgery (PDS) or Interval Debulking Surgery (IDS).

\begin{tabular}{|c|c|c|c|}
\hline \multicolumn{4}{|c|}{ Post-Operative Adverse Events and Mortality } \\
\hline Variables & $\begin{array}{c}\text { PDS } \\
(\mathrm{N}=30(\%))^{*}\end{array}$ & $\begin{array}{c}\text { IDS } \\
(\mathrm{N}=\mathbf{3 0}(\%))^{*}\end{array}$ & p-value \\
\hline Fever & $3(10.0)$ & $7(23.3)$ & 0.166 \\
\hline Hypotension & $7(23.3)$ & $4(13.3)$ & 0.317 \\
\hline Diarrhea & $4(13.3)$ & $4(13.3)$ & 1.00 \\
\hline Nausea \& vomiting & $7(23.3)$ & $5(16.7)$ & 0.519 \\
\hline Hypoalbuminemia & $12(41.4)$ & $11(36.7)$ & 0.711 \\
\hline Electrolyte Imbalance & $11(36.7)$ & $5(16.7)$ & 0.08 \\
\hline Fistula & $3(10.0)$ & $2(6.7)$ & 1.00 \\
\hline Intestinal resection (total) & $6(20)$ & $4(13.3)$ & \\
\hline Small intestinal resection & $2(6.7)$ & $2(6.7)$ & \\
\hline Loop ileostomy & $2(6.7)$ & $0(0.0)$ & 0.726 \\
\hline Colostomy & $2(6.7)$ & $2(6.7)$ & \\
\hline Injury to bladder & $3(10.0)$ & $1(3.3)$ & 0.612 \\
\hline Infection & $11(36.7)$ & $11(36.7)$ & 1.00 \\
\hline Pulmonary complication & $4(13.3)$ & $1(3.3)$ & 0.353 \\
\hline Paralytic ileus & $6(20.0)$ & $0(6.7)$ & 0.024 \\
\hline Renal complication & $2(6.7)$ & $0(0.0)$ & 0.492 \\
\hline Death within 45 days of surgery & $1(3.3)^{* *}$ & $0(0.0)$ & 1.00 \\
\hline
\end{tabular}

${ }^{\star}$ PDS $=$ Primary Debulking Surgery +6 cycle chemotherapy; IDS $=3$ Cycles Neoadjuvant chemotherapy (NACT) + Interval Debulking Surgery +3 cycles chemotherapy. ${ }^{\star *}$ This patient died at home after several days of anorexia and abdominal distention. She was thought to have had an intestinal obstruction.

Table 5. Local recurrence outcomes of sixty patients assigned to either Primary Debulking Surgery (PDS) or Interval Debulking Surgery (IDS).

\begin{tabular}{|c|c|c|c|c|}
\hline \multicolumn{5}{|c|}{$\begin{array}{l}\text { Local Recurrence of Patients During Fifteen Month } \\
\text { Follow-Up Period After Surgery and Chemotherapy }\end{array}$} \\
\hline \multirow{2}{*}{$\begin{array}{l}\text { Presence of tumor or ascites } \\
\text { at different follow-ups }\end{array}$} & \multicolumn{2}{|c|}{ Group } & \multirow{2}{*}{$\begin{array}{l}\text { Fisher's } \\
\text { Exact test }\end{array}$} & \multirow[b]{2}{*}{ p-value } \\
\hline & $\begin{array}{l}\text { PDS }^{*} \\
\text { N (\%) }\end{array}$ & $\begin{array}{l}\text { IDS }^{*} \\
\text { N (\%) }\end{array}$ & & \\
\hline First follow-up (0 to 3 months) & $(\mathrm{n}=30)$ & $(\mathrm{n}=30)$ & & \\
\hline Mass & $0(0.0)$ & $0(0.0)$ & - & - \\
\hline Second follow-up (3 to 6 months) & $(n=29)$ & $(\mathrm{n}=30)$ & & \\
\hline Mass with ascites & $1(3.4)$ & $0(0.0)$ & 0.001 & 1.00 \\
\hline
\end{tabular}




\section{Continued}

\begin{tabular}{ccccc}
\hline Third follow- up (6 to 9 months $)$ & $(\mathrm{n}=29)$ & $(\mathrm{n}=30)$ & & \\
Mass & $2(6.9)$ & $0(0.0)$ & & \\
Ascites & $1(3.4)$ & $0(0.0)$ & 2.828 & 0.112 \\
Fourth follow - up (9 to 12 months $)$ & $(\mathrm{n}=29)$ & $(\mathrm{n}=30)$ & & \\
Mass & $3(10.3)$ & $0(0.0)$ & & \\
Mass with ascites & $1(3.4)$ & $0(0.0)$ & 5.119 & 0.024 \\
Ascites & $1(3.4)$ & $0(0.0)$ & & \\
Fifth follow- up (12 to 15 months $)$ & $(\mathrm{n}=29)$ & $(\mathrm{n}=30)$ & & \\
Mass & $5(17.2)$ & $0(0.0)$ & & \\
Mass with ascites & $2(6.9)$ & $0(0.0)$ & 8.984 & 0.002 \\
Ascites & $1(3.4)$ & $0(0.0)$ & & \\
Total Recurrences & $17(56.7 \%)$ & 0 & & \\
\hline
\end{tabular}

${ }^{\star} \mathrm{PDS}=$ Primary Debulking Surgery +6 cycle chemotherapy; IDS = 3 Cycles Neoadjuvant chemotherapy (NACT) + Interval Debulking Surgery + 3 cycles chemotherapy.

masses and ascites than the IDS group (p-value of 0.024 and 0.002 at 12 months and 15 months of follow-up).

Distant recurrences among both groups are summarized in Table 6. Patients undergoing PDS were more likely to have metastases to the liver and supraclavicular lymph nodes than patients in the IDS group. One patient in the PDS group developed lung metastases in addition to hepatic and peritoneal disease. In the IDS group, patients' complete response (CR) was found in $22(73.3 \%)$ patients while partial response (PR) was noted in six patients (20\%). In two patients (6.7\%) stable disease (SD) was found. In the IDS group, complete response and partial response were found in $22(73.3 \%)$ and six (20\%) patients respectively for patients receiving three cycles of chemotherapy prior to surgery.

The disease-free survival between the groups was compared by using Kaplan-Meier curve. Statistically significant difference in favor of the IDS group was found between the groups by Log Rank (Mantel-Cox) test $\left(\chi^{2}=26.274_{(\mathrm{df}=1)} ; \mathrm{p}<\right.$ 0.001). Median disease-free survival in the PDS group was twelve months while that of the IDS was seventeen months (Figure 1). By 15 months of follow-up, there was one death in the PDS group at 45 days.

\section{Discussion}

\section{Summary of Main Results}

Our results demonstrate that NACT is associated with superior optimal cytoreduction, lower peri-operative morbidity as well as post-surgical morality compared to initial surgery in patients with advanced epithelial ovarian cancer. For patients presenting to NICRH in Bangladesh, NACT followed by IDS has a more favourable outcome than PDS on progression free survival in advanced epithelial ovarian cancer. 


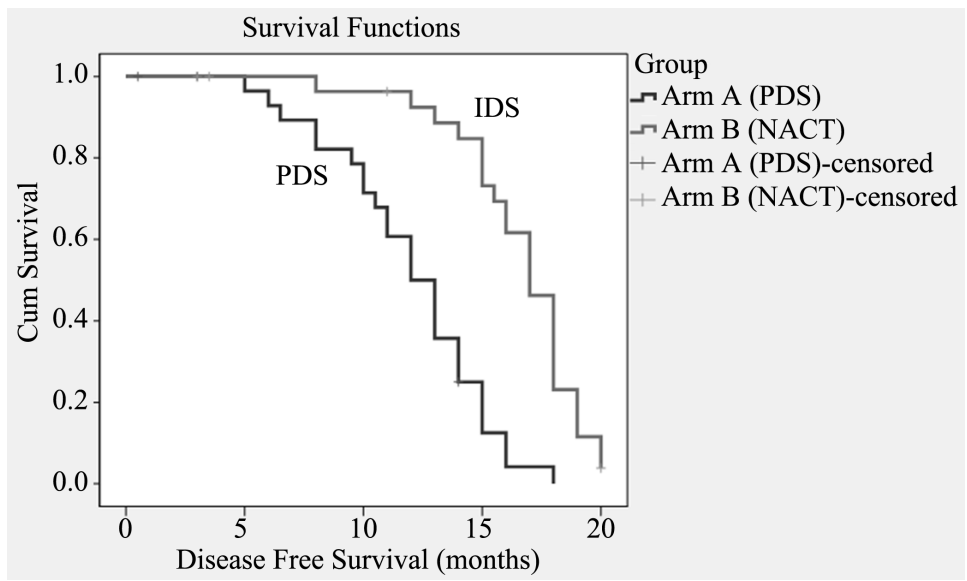

Figure 1. Disease free survival for 30 patients with primary Debulking surgery and 30 patients with interval Debulking surgery. Arm A = PDS +6 cycle chemotherapy; Arm B = 3 Cycles NACT + IDS + 3 cycles chemotherapy.

Table 6. Development distant metastasis for sixty patients assigned to either Primary Debulking Surgery (PDS) or Interval Debulking Surgery (IDS).

\begin{tabular}{|c|c|c|c|c|}
\hline \multicolumn{5}{|c|}{ Distant Metastasis of Patients During Fifteen Month Follow-Up Period } \\
\hline \multirow[b]{2}{*}{ Metastasis } & \multicolumn{2}{|c|}{ Group } & \multirow{2}{*}{$\begin{array}{l}\text { Fisher's } \\
\text { Exact test }\end{array}$} & \multirow[b]{2}{*}{ p-value } \\
\hline & $\begin{array}{l}\text { PDS* } \\
\text { N (\%) }\end{array}$ & $\begin{array}{c}\text { IDS }^{*} \\
\text { N (\%) }\end{array}$ & & \\
\hline \multicolumn{5}{|l|}{ At first follow-up } \\
\hline Peritoneal & $0(0.0)$ & $0(0.0)$ & & \\
\hline \multicolumn{5}{|l|}{ At 6 months follow-up } \\
\hline Peritoneal & $03(10.3)$ & $0(0.0)$ & 3.273 & 0.11 \\
\hline \multicolumn{5}{|l|}{ At 9 months follow-up } \\
\hline Liver & $01(3.4)$ & $0(0.0)$ & & \\
\hline Peritoneal & $03(10.3)$ & $02(6.7)$ & 2.422 & 0.425 \\
\hline Supraclavicular & $01(3.4)$ & $0(0.0)$ & & \\
\hline \multicolumn{5}{|l|}{ At 12 months follow-up } \\
\hline Liver & $01(3.4)$ & $0(0.0)$ & & \\
\hline Peritoneal & $03(10.3)$ & $2(6.7)$ & 2.422 & 0.425 \\
\hline Supraclavicular & $01(3.4)$ & $0(0.0)$ & & \\
\hline \multicolumn{5}{|l|}{ At 15 months follow-up } \\
\hline Lung & $01(3.4)$ & $0(0.0)$ & & \\
\hline Liver & $02(6.9)$ & $0(0.0)$ & 4.878 & 0.258 \\
\hline Peritoneal & $03(10.3)$ & $01(3.3)$ & & \\
\hline Supraclavicular & $02(6.9)$ & $0(0.0)$ & & \\
\hline TOTAL RECURENCES & $21(70 \%)$ & $5(16.7 \%)$ & & \\
\hline
\end{tabular}

${ }^{\star}$ PDS Primary Debulking Surgery $=$ PDS +6 cycle chemotherapy; IDS Interval Debulking Surgery $=3$ Cycles NACT + IDS +3 cycles chemotherapy. 


\section{Results in the Context of Published Literature}

In this study median age of women with advanced ovarian cancer patients was 49 years in the PDS group and 55 years in the IDS group. This is a decade younger than the median age reported in the western literature [12]. The exact reason for this age difference is not known; however, this could reflect the overall demographic profile of population with a relatively younger population than the West. However, an Indian study showed that the median age of women with EOC was 52 years [13]. In SCORPION trial it was noted that the median age of PDS group was 54 years and 55 years in NACT-IDS group [14].

In our study no significant difference was noted between body mass indices. Distension of the abdomen was the chief complain in both groups. Pain and a mass were present in ten and seven patients respectively in the PDS and IDS groups with the median tumor size of $12.12 \mathrm{~cm}$ and $10.85 \mathrm{~cm}$ respectively. Pre NACT and post NACT CA-125 levels were significantly different and correlates with other international experience. One study showed that IDS patients had significantly lower mean preoperative CA125 values when compared with PDS patients ( $310 \pm 849$ vs. $1933 \pm 4778 \mathrm{U} / \mathrm{ml}, \mathrm{p}<0.001)$ [15].

The ECOG (Eastern Cooperative Oncology Group) performance status of the patients was as follows: $83.3 \%$ of the PDS patients had an ECOG status 0 or 1 , whereas this was the case for $73.3 \%$ of the IDS patients. 36.7\% PDS patients had an ECOG status 2 and $46.7 \%$ had an ECOG status 2 and thus was not statistically significant. Other studies also showed almost similar results [15] [16] [17].

In the PDS group, the median length of surgery was 2.75 hours compared to 2.5 hours for the IDS group. This difference was statistically significant. A German study showed that the mean operative time was $4.44 \pm 1.7$ hours in PDS patients $(p=0.054)$ [15]. In total, 218 patients $(60.2 \%)$ were operated on for more than four hours, whereas this was the case for 20 IDS patients (50\%) and 198 PDS patients (61.5\%). Another study reported a shorter duration of surgery and less transfusion needed in those patients treated by NACT [18]. In our study, the amount of blood loss in PDS patients was significantly higher than in IDS patients. Similar results were also noticed in other international studies [3] [4] [19].

Highly significant differences between IDS and PDS patients were noticed in the sites of tumor involvement and postoperative tumor residuals. A complete tumour resection (R0) could be obtained in $80 \%$ of IDS patients versus $43 \%$ of PDS patients similar to other studies. [13] [15] [20].

In our study, CA 125 normalized in $73.3 \%$ and dropped in $20 \%$ patients respectively for patients receiving three cycles of chemotherapy prior to surgery. The impact of chemotherapy was also seen in the differences in the amount of ascitic fluid found in the PDS group which was significantly higher than in the IDS group. Chemotherapy responsive disease has been reported by other groups as well [21] [22] [23] [24]. Parameters of surgical aggressiveness (blood loss rates, ICU stays, and total hospital stay) were significantly lower in NACT group than PDS group [25]. 
In current study, the mean follow-up period was 15 months for the entire group. The follow-up range of both subgroups was identical. More instances of recurrence occurred in PDS than IDS patients $(\mathrm{p}=0.021)$. In contrast, in a study conducted in Italy showed that during the study period, 123 recurrences (70.3\%) were observed, with a statistically significant higher proportion of patients in the IDS group experiencing recurrent disease compared to women receiving PDS (76.3\% vs. $50.0 \%, \mathrm{p}=0.001)$ [26].

In this study, progression free survival between the groups was compared by using Kaplan-Meier curve. Statistically significant differences in favor of NACT was found between the groups by Log Rank (Mantel-Cox) test $\left(\chi^{2}=26.274_{(\mathrm{df}=1)}\right.$; $\mathrm{p}<0.001)$. Median progression free survival in PDS group was twelve months while that of the NACT followed by IDS group was seventeen months. In a cohort of Indian patients with advanced epithelial ovarian cancer treated with neoadjuvant chemotherapy, the median progression free survival was 15.15 months 95\% confidence interval $[\mathrm{CI}]$ and the median overall survival (OS) was 34.73 months [13]. A multivariate analysis of their study revealed that optimal cytoreduction and number of NACT cycles were significantly associated with PFS and optimal cytoreduction. Similarly, in another report, the median overall survival time was 28 months in PDS group and 25 months in NACT group with a p value of 0.5. [25].

Based on the result of meta-analysis of different RCTs, there were no significant differences in the progression free survival (PFS) and overall survival of patients with advanced ovarian cancer based on PDS versus IDS [27] [28] [29]. When deciding whether a patient is a candidate for primary debulking surgery, with an acceptable level of morbidity, the clinician must consider both the burden of disease and the patient's comorbidities. Laparoscopy, in addition to axial $\mathrm{CT}$ and MRI may provide information about the disease burden and the ability to surgically resect the disease [12] [14] [30] [31]. The difference between progression free survival among patients undergoing primary versus interval cytoreductive surgery may be in part due to differences in complete resections. In only $43 \%$ of the PDS group compared to $80 \%$ of the IDS group achieved R0 complete surgical resections. Our data supports the importance of complete surgical cytoreduction as a prognostic indicator.

\section{Strengths and Weaknesses}

All patients were consecutively operated by gynaecologic-oncologic surgeons. Only patients with FIGO stages III and IV were included in this analysis. The present study had some limitations. The study was conducted in a single centre in Dhaka city which may not be representative for the whole population. The sample size was small in the present study. The study period of present study was short. A longer follow-up will help document overall survival of patients undergoing PDS versus NACT and IDS.

\section{Conclusion}

Ovarian cancer frequently presents at an advanced stage, and it may not be possi- 
ble to remove all this disease during surgery. In Bangladesh, NACT is associated with superior optimal cytoreduction, lower peri-operative morbidity as well as post-surgical morality compared to initial surgery in patients with advanced epithelial ovarian cancer. NACT followed by IDS has a more favorable outcome than PDS on progression free survival in advanced epithelial ovarian cancer. Our study supports the findings of multiple other reports that NACT before surgery is an acceptable standard of care for women with advanced ovarian cancer.

\section{Contributors Study Design}

FK, SP. Data acquisition: FK, Central audit: SP. Data interpretation: KA, NIJ, Manuscript writing: FK, NIJ, AKG. Manuscript review: FK, SP, NIJ.AKG.

\section{Conflicts of Interest}

The authors have no conflicts of interest to disclose.

\section{References}

[1] Siegel, R.L., Miller, K.D., Fuchs, H.E. and Jemal, A. (2021) Cancer Statistics, 2021. CA: A Cancer Journal for Clinicians, 71, 7-33. https://doi.org/10.3322/caac.21654

[2] Minig, L., Zorrero, C., Iserte, P.P. and Poveda, A. (2015) Selecting the Best Strategy of Treatment in Newly Diagnosed Advanced-Stage Ovarian Cancer Patients. World Journal of Methodology, 5, 196-202. https://doi.org/10.5662/wjm.v5.i4.196

[3] Allen, D.G., Heintz, A.P. and Touw, F.W. (1995) A Meta-Analysis of Residual Disease and Survival in Stage III and IV Carcinoma of the ovary. European Journal of Gynaecological Oncology, 16, 349-356.

[4] Bristow, R.E., Tomacruz, R.S., Armstrong, D.K., Trimble, E.L. and Montz, F.J. (2002) Survival Effect of Maximal Cytoreductive Surgery for Advanced Ovarian Carcinoma during the Platinum Era: A Meta-Analysis. Journal of Clinical Oncology, 20, 1248-1259. https://doi.org/10.1200/JCO.2002.20.5.1248

[5] Coleridge, S.L., Bryant, A., Kehoe, S. and Morrison, J. (2021) Neoadjuvant Chemotherapy before Surgery versus Surgery Followed by Chemotherapy for Initial Treatment in Advanced Ovarian Epithelial Cancer. Cochrane Database of Systematic Reviews, No. 7, Article No. CD005343. https://doi.org/10.1002/14651858.CD005343.pub6

[6] Xu, Z., Becerra, A.Z., Justiniano, C.F., Aquina, C.T., Fleming, F.J., Boscoe, F.P., et al. (2020) Complications and Survivorship Trends after Primary Debulking Surgery for Ovarian Cancer. Journal of Surgical Research, 246, 34-41.

https://doi.org/10.1016/j.jss.2019.08.027

[7] Markauskas, A., Mogensen, O., de Pont Christensen, R. and Jensen, P.T. (2014) Primary Surgery or Interval Debulking for Advanced Epithelial Ovarian Cancer: Does It Matter? International Journal of Gynecological Cancer, 24, 1420-1428. https://doi.org/10.1097/IGC.0000000000000241

[8] Wright, A.A., Bohlke, K., Armstrong, D.K., Bookman, M.A., Cliby, W.A., Coleman, R.L., et al. (2016) Neoadjuvant Chemotherapy for Newly Diagnosed, Advanced Ovarian Cancer: Society of Gynecologic Oncology and American Society of Clinical Oncology Clinical Practice Guideline. Journal of Clinical Oncology, 34, 3460-3473. https://doi.org/10.1016/S1470-2045(18)30566-7

[9] Vergote, I., Coens, C., Nankivell, M., Kristensen, G.B., Parmar, M.K.B., Ehlen, T., et 
al. (2018) Neoadjuvant Chemotherapy versus Debulking Surgery in Advanced Tubo-Ovarian Cancers: Pooled Analysis of Individual Patient Data from the EORTC 55971 and CHORUS Trials. The Lancet Oncology, 19, 1680-1687. https://doi.org/10.1016/S1470-2045(18)30566-7

[10] Patel, A., Iyer, P., Matsuzaki, S., Matsuo, K., Sood, A.K. and Fleming, N.D. (2021) Emerging Trends in Neoadjuvant Chemotherapy for Ovarian Cancer. Cancers, 13, Article No. 626. https://doi.org/10.3390/cancers13040626

[11] Wittekind, C., Compton, C.C., Greene, F.L. and Sobin, L.H. (2002) TNM Residual Tumor Classification Revisited. Cancer, 94, 2511-2516. https://doi.org/10.1002/cncr.10492

[12] Clarke, T., Galaal, K., Bryant, A. and Naik, R. (2014) Evaluation of Follow-up Strategies for Patients with Epithelial Ovarian Cancer Following Completion of Primary Treatment. Cochrane Database of Systematic Reviews, No. 9, Article No. CD006119. https://doi.org/10.1002/14651858.CD006119.pub3

[13] Maheshwari, A., Kumar, N., Gupta, S., Rekhi, B., Shylasree, T.S., Dusane, R., et al. (2018) Outcomes of Advanced Epithelial Ovarin Cancer Treated with Neoadjuvant Chemotherapy. Indian Journal of Cancer, 55, 5054.

https://doi.org/10.4103/ijc.IJC_468_17

[14] Fagotti, A., Ferrandina, G., Vizzielli, G., Fanfani, F., Gallotta, V., Chiantera, V., et al. (2016) Phase III Randomised Clinical Trial Comparing Primary Surgery versus Neoadjuvant Chemotherapy in Advanced Epithelial Ovarian Cancer with High Tumour Load (SCORPION Trial): Final Analysis of Peri-Operative Outcome. European Journal of Cancer, 59, 22-33. https://doi.org/10.1016/j.ejca.2016.01.017

[15] Sehouli, J., Savvatis, K., Braicu, E.I., Schmidt, S.C., Lichtenegger, W. and Fotopoulou, C. (2010) Primary versus Interval Debulking Surgery in Advanced Ovarian Cancer: Results from a Systematic Single-Center Analysis. International Journal of Gynecological Cancer, 20, 1331-1340.

[16] Zheng, H. and Gao, Y.N. (2012) Primary Debulking Surgery or Neoadjuvant Chemotherapy followed by Interval Debulking Surgery for Patients with Advanced Ovarian Cancer. Chinese Journal of Cancer Research, 24, 304-309.

[17] Revaux, A., Rouzier, R., Ballester, M., Selle, F., Daraï, E. and Chéreau, E. (2012) Comparison of Morbidity and Survival between Primary and Interval Cytoreductive Surgery in Patients after Modified Posterior Pelvic Exenteration for Advanced Ovarian Cancer. International Journal of Gynecological Cancer, 22, 1349-1354. https://doi.org/10.1097/IGC.0b013e318265d358

[18] Kuhn, W., Rutke, S., Späthe, K., Schmalfeldt, B., Florack, G., von Hundelshausen, B., et al. (2001) Neoadjuvant Chemotherapy Followed by Tumor Debulking Prolongs Survival for Patients with Poor Prognosis in International Federation of Gynecology and Obstetrics Stage IIIC Ovarian Carcinoma. Cancer, 92, 2585-2591.

[19] Chishti, U. and Aziz, A.B. (2015) Primary Debulking Surgery versus Neo-Adjuvant Chemotherapy in Stage III/IV Ovarian Cancer: Comparison of Perioperative Morbidity and Survival Data in Pakistani Women. Journal of Pakistan Medical Association, 65, 306-309.

[20] Chern, J.Y. and Curtin, J.P. (2016) Appropriate Recommendations for Surgical Debulking in Stage IV Ovarian Cancer. Current Treatment Options in Oncology, 17, Article No. 1. https://doi.org/10.1007/s11864-015-0380-2

[21] Eisenkop, S.M., Spirtos, N.M., Friedman, R.L., Lin, W.C., Pisani, A.L. and Perticucci, S. (2003) Relative Influences of Tumor Volume before Surgery and the Cytoreductive Outcome on Survival for Patients with Advanced Ovarian Cancer: A Pros- 
pective Study. Gynecologic Oncology, 90, 390-396. https://doi.org/10.1016/S0090-8258(03)00278-6

[22] Onda, T., Satoh, T., Saito, T., Kasamatsu, T., Nakanishi, T., Nakamura, K., et al. (2016) Comparison of Treatment Invasiveness between Upfront Debulking Surgery versus Interval Debulking Surgery Following Neoadjuvant Chemotherapy for Stage III/IV Ovarian, Tubal, and Peritoneal Cancers in a Phase III Randomised Trial: Japan Clinical Oncology Group Study JCOG0602. European Journal of Cancer, 64, 22-31. https://doi.org/10.1016/j.ejca.2016.05.017

[23] Ma, D.-Y., , Tan, B.-X., Li, X.-F., Zhou Y.-Q. and Cai, H.-W. (2013) A Meta-Analysis: Neoadjuvant Chemotherapy versus Primary Surgery in Ovarian Carcinoma FIGO Stage III and IV. World Journal of Surgical Oncology, 11, Article No. 267. https://doi.org/10.1186/1477-7819-11-267

[24] Morrison, J., Haldar, K., Kehoe, S. and Lawrie, T.A. (2012) Chemotherapy versus Surgery for Initial Treatment in Advanced Ovarian Epithelial Cancer. Cochrane Database of Systematic Reviews, No. 8, Article No. CD005343. https://doi.org/10.1002/14651858.CD005343.pub3

[25] Hegazy, M.A., Hegazi, R.A., Elshafei, M.A., Setit, A.E., Elshamy, M.R., Eltatoongy, M. and Halim, A.A. (2005) Neoadjuvant Chemotherapy versus Primary Surgery in Advanced Ovarian Carcinoma. World Journal of Surgical Oncology, 3, Article No. 57. https://doi.org/10.1186/1477-7819-3-57

[26] Petrillo, M., Ferrandina, G., Fagotti, A., Vizzielli, G., Margariti, P.A., Pedone, A.L., Nero, C., Fanfani, F. and Scambia, G. (2013) Timing and Pattern of Recurrence in Ovarian Cancer Patients with High Tumor Dissemination Treated with Primary Debulking Surgery versus Neoadjuvant Chemotherapy. Annals of Surgical Oncology, 20, 3955-3960. https://doi.org/10.1245/s10434-013-3091-6

[27] Vergote, I., Tropé, C.G., Amant, F., Kristensen, G.B., Ehlen, T., Johnson, N., et al. (2010) Neoadjuvant Chemotherapy or Primary Surgery in Stage IIIC or IV Ovarian Cancer. The New England Journal of Medicine, 363, 943-953. https://doi.org/10.1056/NEJMoa0908806

[28] Kehoe, S., Hook, J., Nankivell, M., Jayson, G.C., Kitchener, H., Lopes, T., et al. (2015) Primary chemoTherapy versus Primary surgery for Newly Diagnosed Advanced Ovarian Cancer (CHORUS): An Open-Label, Randomised, Controlled, Non-Inferiority Trial. Lancet, 386, 249-257. https://doi.org/10.1016/S0140-6736(14)62223-6

[29] Qin, M., Jin, Y., Ma, L., Zhang, Y.Y. and Pan, L.Y. (2017) The Role of Neoadjuvant Chemotherapy Followed by Interval Debulking Surgery in Advanced Ovarian Cancer: A Systematic Review and Meta-Analysis of Randomized Controlled Trials and Observational Studies. Oncotarget, 9, 8614-8628.

https://doi.org/10.18632/oncotarget.23808

[30] Ba, M., Long, H., Zhang, X., Yan, Z., Wang, S., Wu, Y., Gong, Y. and Cui, S. (2019) Ascites Do Not Affect the Rate of Complete Cytoreductive Surgery and Prognosis in Patients with Primary Ovarian Cancer with Ascites Treated with Hyperthermic Intraperitoneal Chemotherapy. Oncology Letters, 18, 2025-2033.

https://doi.org/10.3892/ol.2019.10493

[31] Berek, J.S., Kehoe, S.T., Kumar, L. and Friedlander, M. (2018) Cancer of the Ovary, Fallopian Tube, and Peritoneum. International Journal of Gynecology \& Obstetrics, 143, 59-78. https://doi.org/10.1002/ijgo.12614 